\title{
Plant communities, wetlands and landscapes of the Parque Nacional de Banhine, Moçambique
}

\author{
M. STALMAnS and M. WisharT
}

Stalmans, M. and M. Wishart. 2005. Plant communities, wetlands and landscapes of the Parque Nacional de Banhine, Moçambique. Koedoe 48(2): 43-58. Pretoria. ISSN 00756458.

The Parque Nacional de Banhine (Banhine National Park) was proclaimed during 1972. It covers 600000 ha in Moçambique to the east of the Limpopo River. Until recently, this park, originally and popularly known as the 'Serengeti of Moçambique', was characterised by neglect and illegal hunting that caused the demise of most of its large wildlife. New initiatives aimed at rehabilitating the park have been launched within the scope of the Greater Limpopo Transfrontier Park. A vegetation map was required as input to its management plan. The major objectives of the study were firstly to understand the environmental determinants of the vegetation, secondly to identify and describe individual plant communities in terms of species composition and structure and thirdly to delineate landscapes in terms of their plant community and wetland make-up, environmental determinants and distribution. A combination of fieldwork and analysis of LANDSAT satellite imagery was used. A total of 115 sample plots were surveyed. Another 222 sample points were briefly assessed from the air to establish the extent of the different landscapes. The ordination results clearly indicate the overriding importance of moisture availability in determining vegetation composition in the Parque Nacional de Banhine. Eleven distinct plant communities were recognised. They are described in terms of their structure, composition and distribution. These plant communities have strong affinities to a number of communities found in the Limpopo National Park to the west. The sandveld community is relatively the most species-rich of all communities. Different combinations of these plant communities can be grouped in five major landscapes, namely the Wetland, Grassland, Mopane, Sandveld and Androstachys landscape. These different landscapes hold six different wetland types as defined by the RAMSAR classification. The landscapes with their individual plant communities and wetland types represent a unique combination of habitats that have great intrinsic conservation value. These habitats are key to the long-term maintenance and survival of a diverse avifauna, including the original ostrich population, as well as wattled cranes.

Key words: Parque Nacional de Banhine, Greater Limpopo Transfrontier Park, TFCA, landscape, wetland.

M. Stalmans, International Conservation Services, P.O. Box 19139, Nelspruit, 1200 Republic of South Africa (stalmans@ics-consulting.co.za); M. Wishart, Freshwater Research Unit, Department of Zoology University of Cape Town, Rhodes Gift, 7701 Republic of South Africa.

\section{Introduction}

The Parque Nacional de Banhine (PNB) was proclaimed during 1972. It covers 600000 ha in Moçambique to the east of the Limpopo River and forms one of the major components of the Greater Limpopo Transfrontier Park (Fig. 1). A vegetation map was required as one of the essential building blocks for the drafting of its management plan (Anonymous 2002).

Little or no botanical surveys were carried out in Moçambique between 1980 and 1994 during the long period of internal conflict that affected much of the country (Anonymous 1997). The extent of the area, its relative inaccessibility due to poor road infrastructure, and the limited time available pre- 


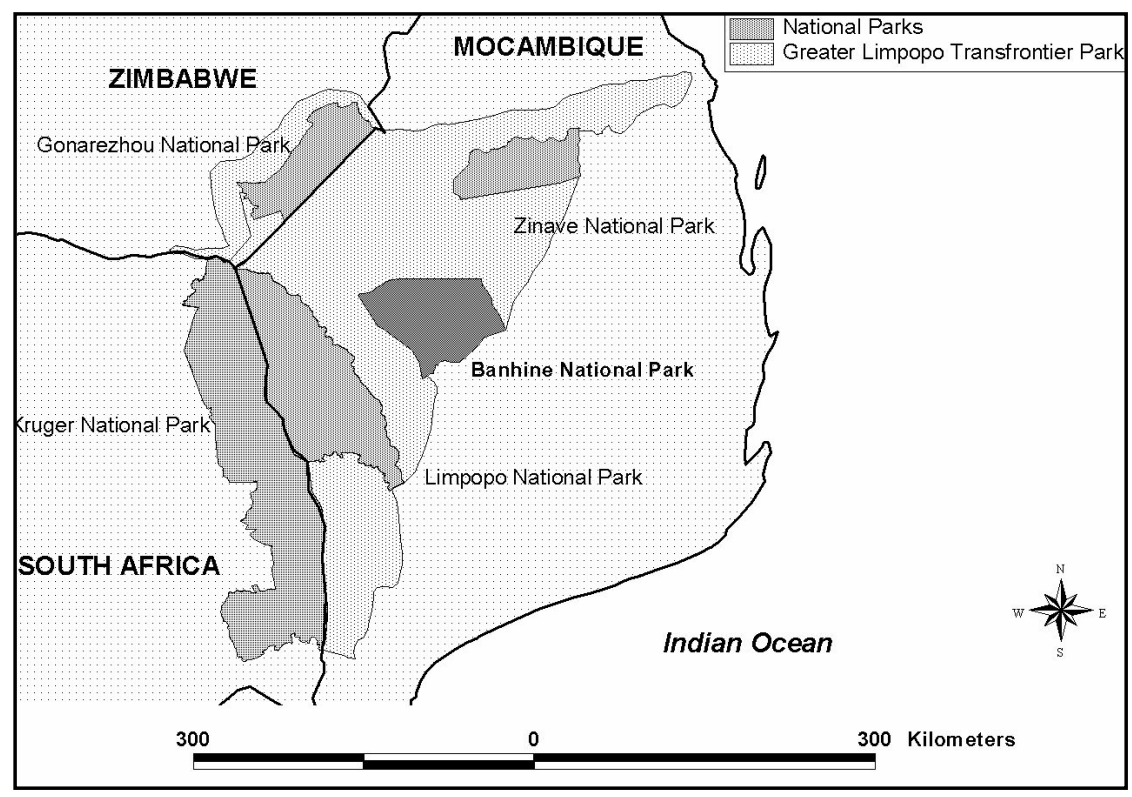

Fig. 1. Locality map of the Parque Nacional de Banhine.

cluded a traditional fine-scale vegetation description and map of the PNB. Such a finescale input is in any case likely to be too detailed for the scale of management envisaged, certainly in the short to medium term.

Vegetation is often used as a surrogate or building block for the definition of habitats (Timberlake et al. 1993). The use of broad habitat units defined by a combination of environmental factors and vegetation would probably represent the most useful input for the drafting of the management plan. This is because such units have relevance to different species of wildlife, they may differ in their ecological capacity and availability of water, they might require different fire regimes, and they will differ in their sensitivity to utilisation and development.

As both the Limpopo National Park and the PNB form major components of the Greater Limpopo Transfrontier Park, it was decided to build on the work recently completed in the Limpopo National Park (Stalmans et al. 2004). A similar conceptual approach was followed whereby landscapes were mapped explicitly whereas the embedded plant communities are implicit. A landscape is defined as 'an area with a specific geomorphology, climate, soil vegetation pattern and associated fauna' (Gertenbach 1983).

The objectives of this study were firstly to understand the environmental determinants of the vegetation, secondly to identify and describe individual plant communities in terms of species composition and structure, and thirdly to identify and delineate landscapes in terms of their plant community and wetland make-up, environmental determinants and occurrence.

This is the second in a series of three articles on the vegetation of the Limpopo, Banhine and Zinave National Parks that are located in the Moçambican component of the Greater Limpopo Transfrontier Park. Difficult access, limited resources and a lack of previously published information have severely limited the sampling intensity, the extent of the descriptions and the detail of the map- 
ping. Nevertheless, it is hoped that these first published accounts of the vegetation and landscapes of these parks will provide a basis on which further research projects can expand, much as the level of knowledge of the Kruger National Park has been improved upon over the years.

\section{Study area}

The physical environment largely determines the vegetation composition and structure. The Parque Nacional de Banhine is situated between latitudes $22^{\circ} 30^{\prime}-23^{\circ} 20^{\prime} \mathrm{S}$ and longitudes $32^{\circ} 15^{\prime}-33^{\circ} 25^{\prime} \mathrm{E}$ in the Gaza Province of Moçambique (Fig. 1). Total area is ca. 600000 ha. The PNB forms part of the Greater Limpopo Transfrontier Park with the Limpopo National Park to the west and the Zinave National Park to the north-east. According to the Köppen classification the area has a warm arid climate with a dry winter and a mean annual temperature exceeding $18^{\circ} \mathrm{C}$ (van Rooyen et al. 1981). A mean annual rainfall value of $399 \mathrm{~mm}$ applies to the western half of the PNB and $427 \mathrm{~mm}$ to the eastern half using the grid at 0.5 degree longitude/latitude resolution of the Leemans \& Cramer (1991) database. Considerable variations can be expected within and between seasons (Kelly \& Walker 1976). The highest elevation is on the north-western boundary at $181 \mathrm{~m}$ above sea level. The area dips generally in a south-easterly direction with the lowest point being at $69 \mathrm{~m}$ asl on the eastern boundary. The area is underlain by arenaceous and argillaceous sediments with colluvium in the east (Anonymous 1995). The PNB is covered with a pale grey sandy soil mantle that overlies a layer of calcrete about seven metres below the surface. Very occasionally, there are broken lines of calcrete that reach the surface and extend for distances of up to a hundred metres. The PNB represents a converging endorheic delta-type system with limited overflow (Tinley pers. comm. 2002). A number of ephemeral streams converge from the northwest into a delta-type system forming an endorheic basin with thin alluvial deposits.
An overflow is present on the eastern boundary, draining into the Changane River (Fig. 2). The PNB falls within the Mopane vegetation of the Sudano-Zambezian Region as described by Werger \& Coetzee (1978). Mopaneveld has been described for the hot, dry valley bottom of the Limpopo River in Moçambique (Wild \& Barbosa 1967). The area was formerly often popularly referred to as the 'Serengeti of Moçambique' because of the large numbers of zebra, wildebeest and eland that occupied its wide-open grasslands. Most of this diverse and numerous large herbivore component has been lost over the last decades, mostly through indiscriminate and illegal hunting. There are approximately 2000-3000 people living in and adjacent to the PNB in 11 villages. These people are highly dependent on the direct consumption of park resources for day-to-day survival, including basic household needs of shelter, water, food and medicines, crop and livestock production.

\section{Methods}

\section{Sampling}

A total of 115 plots of $40 \times 40$ m were subjectively located in representative stands of

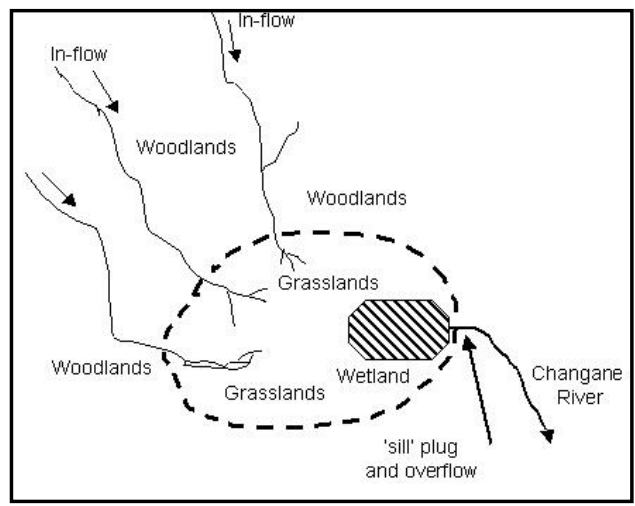

Fig. 2. Schematic representation of the endorheic wetland system of the Parque Nacional de Banhine. 


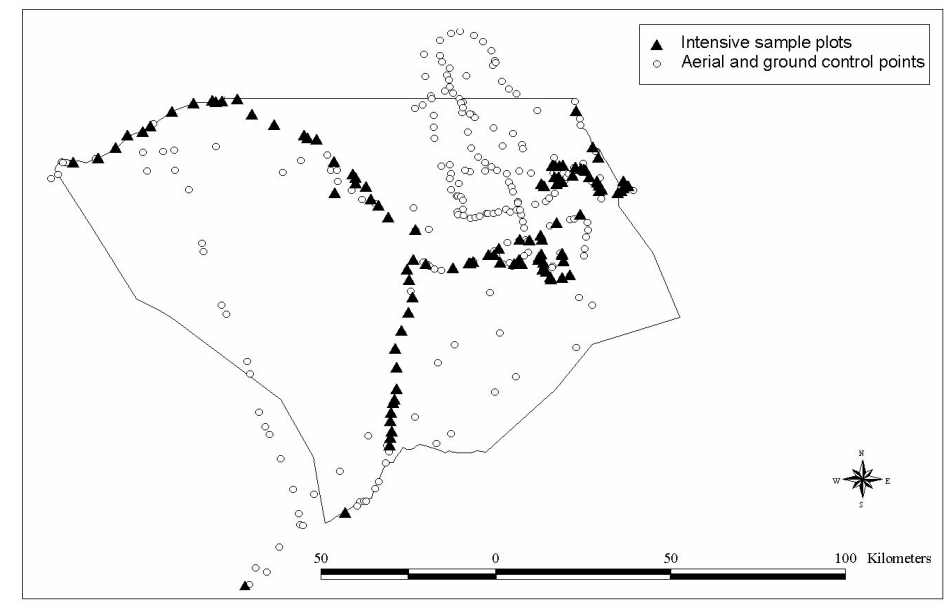

Fig. 3. Position of vegetation sample plots and control points in the Parque Nacional de Banhine.

vegetation to cover the variation in elevation, soils and terrain position. The limited road network was used during the ground survey (Fig. 3). Edwards' (1983) structural classes were used to describe the overall structural properties of the sampled plots. Overall cover was estimated for the woody, grass, forb and geophyte components, respectively, using the semi-quantitative measures of the Braun Blanquet approach (Mueller-Dombois \& Ellenberg 1974). Cover and height classes were recorded for individual woody and grass species. Records of environmental data included GPS position, geology, landscape position (Land Type Survey Staff 1989), slope steepness, soil texture (using the sausage method (National Working Group for Vegetation Ecology 1986)) and rockiness. Fieldwork was undertaken from May to June 2002. Access to the study area can be very difficult due to flooding during summer. Vegetation sampling subsequently had to be postponed till the end of the summer season into winter although this is not ideal in terms of plant species identification.

In order to further increase sampling intensity, so-called 'pseudo-plots' were also used. These consisted of a GPS point and subjec- tive visual assessment relative to the formally surveyed sites. A total of 222 such pseudoplots were assessed during several fixedwing and microlight flights (Fig. 3).

\section{Analysis}

Data were analysed through a combination of classification and ordination techniques. Classification is used to identify groups and to impose structure to raw data. Ordination aims at arranging species and samples in a low-dimensional space such that similar entities are close by and dissimilar entities far apart.

A TWINSPAN classification (Hill 1979) was performed on the sample data. Two-way indicator species analysis (TWINSPAN) is a polythetic divisive technique based on reciprocal averaging ordination (Gauch 1982). It is one of the preferred hierarchical techniques because of its effectiveness and robustness. It results in the definition of communities, each characterised by its own distinctive species combination. Although more contemporary and sophisticated software packages are available for vegetation classification, TWINSPAN's simplicity and 
robustness were appealing within the constraints of this particular study.

The CANOCO package (Ter Braak 1992) was selected to analyse relationships between the data set of 115 plots by 168 species and the underlying environmental factors. CANOCO allows for canonical ordination. This is an intermediate technique that combines aspects of regular ordination with aspects of regression (Jongman et al. 1987). CCA (Canonical Correspondence Analysis) was used. The resulting ordination diagram expresses not only the pattern of variation in species composition but also the main features of species distributions along the gradient of environmental variables (Ter Braak 1986).

\section{Delineation of landscapes}

The relevant landscapes for the PNB were identified using the knowledge gained through the ordination and classification of the PNB field data. A combined approach was used to map these landscapes using the available soils map, the existing land cover map and the LANDSAT image. The land cover map ("Carta de Uso e Cobertura da Terra") has been derived for Moçambique from LANDSAT satellite imagery at a scale of 1:250,000 (Anonymous 1999). A 'best fit' map of the landscapes was subjectively drawn by matching the individual land cover polygons to the field sampling data and the 222 pseudoplots. Furthermore, polygon boundaries were manually edited following visual inspection of the satellite image. The coverage of the polygons by the available data set was assessed in order to derive a measure of certainty or uncertainty regarding the quality of the final landscape map.

\section{Results and discussion}

\section{Causal factors of vegetation pattern in the} $P N B$

The first ordination run with the full set of 115 vegetation plots resulted in two distinct 'clouds' of sample plots in ordination space (Fig. 4). The environmental variables

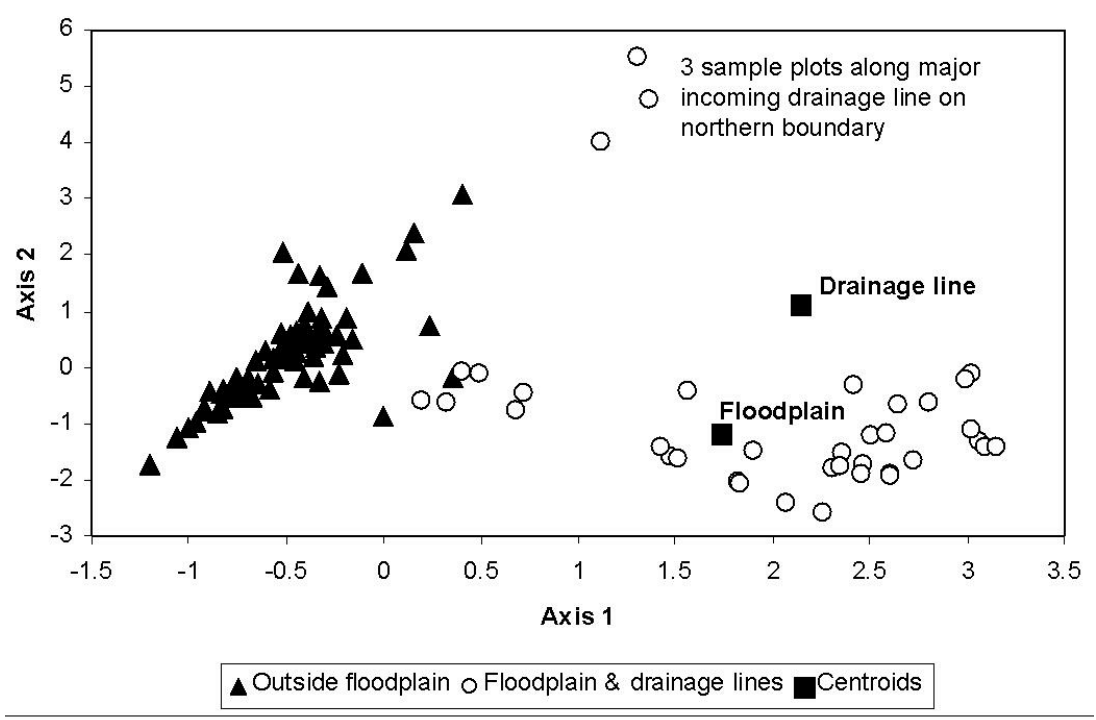

Fig. 4. CANOCO ordination of 115 vegetation sample plots in the Parque Nacional de Banhine. Note dense cloud of sample plots on left side of diagram with outlying plots to the right that represent vegetation in areas with high moisture availability. 


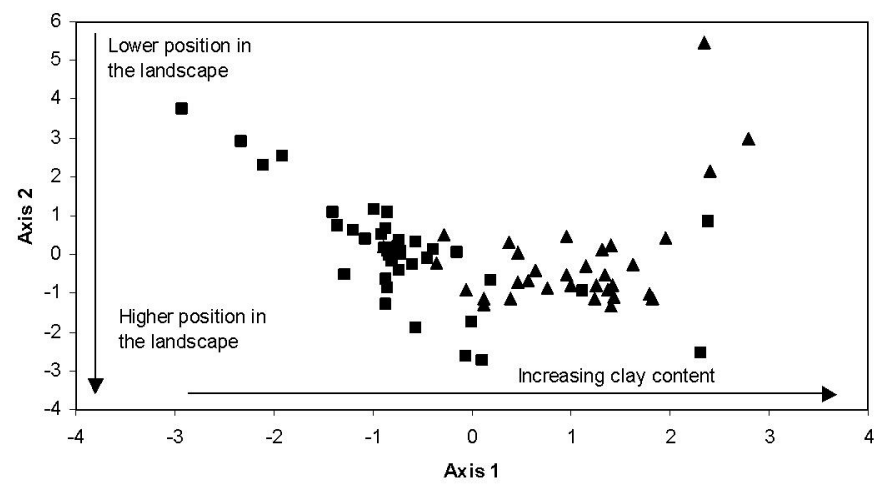

- Mopane < $5 \%$ cover $\Delta$ Mopane > 5\% cover

Fig. 5. CANOCO ordination of 73 vegetation sample plots in the Parque Nacional de Banhine (excluding sample plots along major drainage lines, on floodplains and on termite mounds).

'floodplain' had a high canonical coefficient of 0.74 with the first axis and 'drainage line' had a canonical coefficient of 0.56 .

The 37 plots on the right of the diagram represent all the pans, riverbanks and reed beds that were sampled (Fig. 4). The amount of available moisture as determined through landscape position therefore represents a major environmental determinant of vegetation composition along the first ordination axis. The different sample scores of a specific environmental variable are represented within the ordination diagram by a single point, called the 'centroid'. The grasses Cynodon dactylon and Eragrostis cf. heteromera are typical of these floodplain conditions. The woody species Mimusops obtusifolia, Grewia sulcata, Spirostachys africana and Acacia robusta are typical for the fringes of the major drainage lines feeding the Banhine system from the north.

The 37 plots associated with the floodplain and drainage line were removed from the data set and a second ordination was run. The resulting diagram identifies an outlier in the mopane veld on the northern boundary with the grass layer being dominated by Cymbopogon. The other outliers represent the bush clumps found in the floodplain that are dominated by Xanthocercis zambesiaca in association with Salvadora persica, Allophylus africanus, Ficus capreifolia, Maclura africana and Rhus guenzii. These bush clumps on termite mounds have a high clay content. The parameter 'soil texture' has a canonical coefficient of 0.89 and $t$-value of 10.3 for the first axis. This clearly indicates the increasing clay content of the soils.

Once again, the five outlying plots were removed and the remaining data set was ordinated. The split between 'sandveld' and non-sandveld sample plots is very clear along the gradient of decreasing clay content of the soil along the first ordination axis (Fig. 5). The parameter 'soil texture' has a canonical coefficient of 0.76 and $t$-value of 9.6 for the first axis. There is a weaker gradient in terms of landscape position with crest and upper slope positions negatively correlated to the second axis (canonical coefficients of 0.66 and 0.46 respectively). The non-sandveld sample plots are characterised by mopane Colophospermum mopane. Sandveld has typically no mopane (or only a low cover percentage for this species) with typical sandveld species such as Xerroderris stuhlmannii, Strychnos madagascariensis and Guibourtia conjugata. 


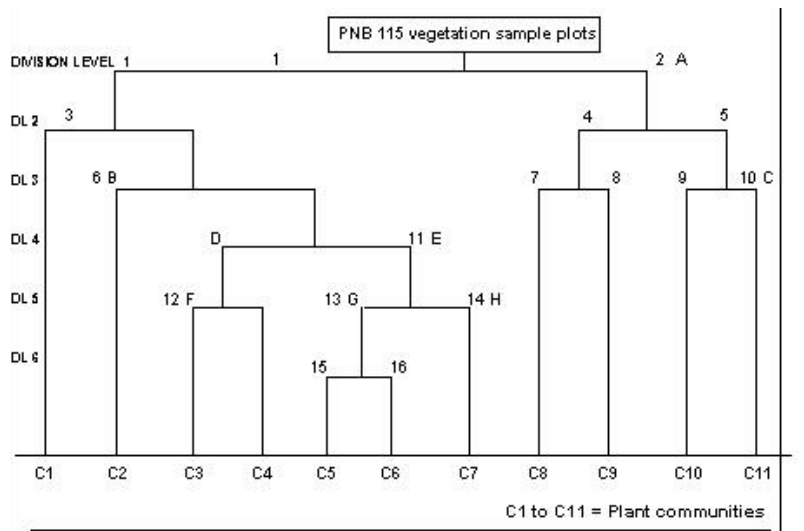

ENVIRONMENTAL CHARACTERISTICS

\begin{tabular}{|c|c|}
\hline $\begin{array}{l}\text { A Floodplains \& pans } \\
\text { C Pans and wetlands } \\
\text { E Sandy soils } \\
G \text { well-drained soils, xeric }\end{array}$ & $\begin{array}{l}\text { B Termitaria } \\
\text { D Loamy sands and clayey soils } \\
\text { F Stream and river banks (seasonal) } \\
\text { H Soils with a high water table }\end{array}$ \\
\hline \multicolumn{2}{|c|}{$\begin{array}{l}\text { INDICATOR SPECIES FOR THE HIERARCHICAL DIVISION } \\
1 \text { Panicum maximum } \\
2 \text { Cynodon dactylon, Eragrostis heteromera, Panicum coloratum, Paspalidium obtusifolit } \\
3 \text { Androstachys johnsonii } \\
4 \text { Hyphaene petersiana, Panicum coloratum, Colophospermum mopane } \\
5 \text { Paspalidium obtusifolium } \\
6 \text { Xanthocercis zambesiaca } \\
7 \text { Acacia borleae } \\
8 \text { Cynodon dactylon } \\
9 \text { Eragrostis heteromera, Cynodon dactylon. } \\
10 \text { Paspalidium obtusifolium } \\
11 \text { Eragrostis pallens, Terminalia sericea, Perotis patens, Xeroderris stuhlmannii } \\
12 \text { Acacia robusta } \\
13 \text { Combretum apiculatum } \\
14 \text { Eragrostis gummiflua, Hyphaene petersiana } \\
15 \text { Urochloa mossambicensis } \\
16 \text { Hugonia orientalis. Pteleopsis myrtifolia }\end{array}$} \\
\hline
\end{tabular}

Fig. 6. TWINSPAN dendrogram for 115 vegetation sample plots in the Parque Nacional de Banhine.

The successive ordination runs clearly indicate the overriding importance of moisture availability (in conjunction with soil texture) in determining vegetation composition in the PNB. Firstly, the obvious differences in moisture availability by virtue of sample positions along drainage lines and in the floodplain came out of the first ordination. Thereafter, the gradient in soil clay content (as a result of underlying geological substrate and landscape position) and landscape position per se (in determining water flow) largely determine soil moisture and nutrient availability.

The interplay of soil moisture and soil nutrient availability conforms to the current understanding of the determinants of savanna. The four-determinant model gives water availability and nutrient availability equal status in establishing the range of possible forms a savanna can assume (Scholes \& Walker 1993). Fire and herbivory then determine the actual form and function within that range. Similarly, Timberlake et al. (1993) consider soil moisture in this environment as a major determinant in the distribution of vegetation types. Soil moisture availability results from the interaction between rainfall, topography, soil texture, soil depth, drainage and rooting habit. Siebert et al. (2003) identified a gradient of decreasing soil moisture availability along the first axis of ordination of more than 2000 sample plots in mopane veld straddling South Africa, Namibia and Botswana. Stalmans (1994) and Stalmans et al. (2004) identified water availability (as controlled by the position of the sample in the landscape and by its soil texture) as the major determinant of vegetation composition in an area adjacent to the Gonarezhou National Park in Zimbabwe and in the Limpopo National Park respectively.

\section{TWINSPAN Dendrogram}

The results from the TWINSPAN classification are presented by means of a hierarchical dendrogram (Fig. 6). Starting from the top of the dendrogram, the set of 115 sample plots is divided into two groups. The left group represents the bulk of the sample plots $(n=83)$. The right group with indicator species Cynodon dactylon, Eragrostis heteromera, Panicum coloratum and Paspalidium obtusifolium represent vegetation associated with seasonally or permanently flooded conditions. These two main divisions are now described separately. 
The Androstachys woodlands and thickets already become a separate entity at Level 2 of the diagram (Community 1). The Xanthocercis zambesiaca bushclumps on termitaria are split off from the remaining plots at Level 3 (Community 2). At Level 4, the division is according to the clay content in the soil profile. The vegetation on more clayey soils is divided into two communities, namely closed woodlands along seasonal drainage lines (Community 3) and typical mopane woodlands (Community 4). The split at Level 5 for the more sandy substrates produces a group of plots located on welldrained soils and Community 7 that is found on sandy soils with a high water table. Finally at Level 6, the remaining plots on sandy soils are split into the sandy variant of the mopane community (Community 5 ) and the true sandveld of Community 6 .

Within the wetland and floodplain vegetation, the split at Level 2 is into units that are wooded or not wooded. At Level 3, in the wooded units, the Acacia borleae shrubland that is found encroaching from the mopane into the grasslands becomes distinct (Community 8). Community 9 represents wooded grasslands. Within the non-wooded unit, the grasslands of the seasonally flooded flats (Community 10) are separated from the pans and true wetland. The latter two communities are differentiated by Cynodon dactylon on seasonally flooded grasslands and Paspalidium obtusifolium as a typical (but not exclusive) exponent of the pans.

\section{Definition of plant communities}

The community concept is applied in its broad sense and reflects a recurring assemblage of grass and woody species of characteristic composition and structure, growing in an area of essentially similar environmental conditions and land use history (adapted from Gabriel \& Talbot (1984)).

The classification outcome was evaluated subjectively against photographs of each sample plot. The main criterion applied was the need for each community to be identifiable in the field by an observer who is not necessarily a trained botanist. Community names were chosen subjectively so as to have practical value in the field through the use of two species which are visually and/or diagnostically important. The communities broadly conform to the lower divisions of the dendrogram and they are therefore discussed from left to right following Fig. 6. A total of 11 communities were identified.

\section{Description of plant communities}

\section{Androstachys johnsonii-Croton pseudopulchellus} Closed Woodlands

This is a species-poor community found on red, deep sandy soils. It consists of an extremely dense, short $(5-10 \mathrm{~m})$ woodland dominated by Androstachys johnsonii. Other species have a very low percentage cover value and biomass. The woody species Croton pseudopulchellus, Guibourtia conjugata, Xeroderris stuhlmannii and Manilkara mochisia are also found in this community. The grass cover is very low with the perennial Panicum maximum and the annual Brachiaria deflexa being the most important species. This community is mostly found on the north-western boundary as well as in the southern corner of the park. It is generally sharply demarcated from other communities and occurs in patches ranging from a few dozen metres in diameter to large areas covering many hectares. This community corresponds to the Androstachys johnsonii-Croton pseudopulchellus Dry Forest described by Van Rooyen et al. (1981) in the northern part of the Kruger National Park and to the Androstachys johnsonii-Guibourtia conjugata Short Forest described by Stalmans et al. (2004) for the Limpopo National Park.

\section{Xanthocercis zambesiaca-Salvadora persica Thickets}

This community occurs as distinct bush clumps with a diameter of 20-30 m on termitaria, mostly on the transition from the grasslands to the wetlands. Each clump is characterized by an emergent Xanthocercis 
zambesiaca (Nyala tree) that is surrounded by a variety of other species forming a fringe around the core of the clump. These other species comprise Allophylus africanus, Grewia sulcata, Rhus guenzii, Ficus capreifolia, Maclura africana and Salvadora persica. The grass layer is poorly developed and consists mostly of Panicum maximum.

\section{Mimusops obtusifolia-Spirostachys africana} Closed Woodlands

This community is found along seasonal rivers, mostly on the northern boundary of the park. This riverine community occupies a narrow strip of $10-20 \mathrm{~m}$ wide along these drainage lines. The most important species apart from the dominant Mimusops obtusifolia and Spirostachys africana are Grewia sulcata, Acacia robusta, Combretum imberbe, Garcinia livingstonei and Ziziphus mucronata. The most important grass species is Panicum maximum.

4 Colophospermum mopane - Urochloa mosambicensis Woodlands

This represents the most extensive 'mopane' vegetation found in the PNB. It occurs on slightly more clayey soils (sandy loam) than the mopane of community 5. Prominent woody species are Combretum apiculatum, Sclerocarya birrea, Dichrostachys cinerea, Dalbergia melanoxylon and Drypetes mossambicensis. A major difference with the community 5 is the marked absence of Terminalia sericea and Xeroderris stuhlmannii, as well as the lower frequency of occurrence and lower cover of Combretum apiculatum. The most important grasses are Panicum maximum, Digitaria eriantha, Schmidtia pappaphoroides, Aristida adscencionis and Heteropogon contortus.

5 Colophospermum mopane - Eragrostis pallens Woodlands

This is still a mopane-dominated community but represents a more 'sandy' variant. In addition to mopane, the woody species Combretum apiculatum, Terminalia sericea,
Xeroderris stuhlmannii, Strychnos madagascariensis, Guibourtia conjugata, Boscia albitrunca and Sclerocarya birrea are important components. The grass component also reflects the more sandy nature of the soils with Panicum maximum, Digitaria eriantha, Perotis patens, Eragrostis pallens and Aristida stipitata. Heteropogon contortus is almost totally absent.

\section{Guibourtia conjugata - Eragrostis pallens Woodlands}

This community is found on deep sandy soils. Characteristic woody species of the 'sandveld' are Hugonia orientalis, Pteleopsis myrtifolia, Cleistanthus schlechteri, Hymenocardia ulmoides and Xylotheca kraussiana. Other important species are the more wide-spread Combretum apiculatum, Terminalia sericea, Strychnos madagascariensis and $S$. spinosa. The grass layer is represented by Eragrostis pallens, Panicum maximum, Tricholaena monachme, Perotis patens and Aristida spp. This particular community very closely resembles the Terminalia sericea-Pogonarthria squarrosa Tree Savanna identified by Van Rooyen et al. (1981) in the Punda Milia area of the Kruger National Park. It also encompasses the Xeroderris stuhlmannii - Combretum apiculatum Tree Savanna of Van Rooyen et al. (1981). These communities in turn are similar to the Terminalia sericea - Eragrostis pallens Low Woodland described for the Limpopo National Park by Stalmans et al. (2004).

\section{Hyphaene petersiana - Eragrostis gummiflua Bushlands}

This community consists of a generally fairly open, but sometimes closed vegetation with a mix of trees and shrubs on the transition from the sandveld to the wetland. In addition to the Hyphaene palms, the trees Terminalia sericea and Garcinia livingstonei are prominent. The grass layer is dominated by Eragrostis gummiflua, E. pallens, Perotis patens and Digitaria eriantha. The palms 
and Eragrostis gummiflua are usually an indication of a high water table.

\section{Acacia borleae Shrublands}

This community also occurs on ecotones, but this time between the mopane woodlands and the grasslands. Besides Acacia borleae and Rhigozum zambesiacum, few other woody species occur in association with Colophospermum mopane. Acacia borleae is generally known to occur on clayey soils. The grass layer is characterised by the dominance of Eragrostis cf. heteromera in association with Sporobolus spp., Paspalum sp. and Eragrostis viscosa.

\section{Cynodon dactylon - Panicum coloratum} Wooded Grasslands

This is an open community with a low cover and diversity of woody species. The most prominent woody species are Hyphaene petersiana, Colophospermum mopane, Acacia nilotica and $A$. xanthophloea. The grass layer is dominated by Cynodon dactylon, Panicum coloratum, Digitaria eriantha and Eragrostis cf. heteromera with occasionally Setaria incrassata and Ischaemum afrum on more clayey and poorly drained soils. The sedge component (family Cyperaceae) is very prominent. A crust of detritus and algae was found on most sample plots. This metaphyton originates as floating algae populations that aggregate along the shore line through wave action and the recession of flood waters (Wetzel 2001). Die-back of trees (including Acacia xanthoploea) as a result of long periods of flooding was observed.

\section{Cynodon dactylon Open Grasslands}

These are open grasslands with hardly any woody species present. They are found in seasonally flooded areas where the high water table prevents (probably in combination with recurrent fires) any permanent presence of trees. The grass layer is dominated by Cynodon dactylon, Eragrostis cf. heteromera and Paspalidium obtusifolium.
Other species are cf. Acroceras macrum, Sporobolus consimilis, Digitaria eriantha and Eragrostis gummiflua. As in community 9 , the sedge component is highly visible. A crust of detritus and algae which is a residue from the flooding occurs. This most likely plays a very important role in nutrient supplementation in a community on sandy soils with limited nutrient content. Below the alluvial plug (Fig. 2), along the banks of the Changane on the eastern boundary, the vegetation indicates almost saline characteristics with the presence of succulent halophytes and Sporobolus spp. (probably S. kentrophyllus). Similar-looking grasslands were observed from the air, $15 \mathrm{~km}$ north-northwest of Pio Cabral. The Cynodon dactylon open grasslands are considered to be 'natural' (given the edaphic control in combination with fires). They do, therefore, not represent a secondary degradation product of savannas that would be expected to occur under the prevailing climatic conditions. This viewpoint is in support of the analysis by Matthews et al. (1999) for the coastal grasslands of Maputaland.

\section{Paspalidium obtusifolium Open Grasslands}

These open grasslands are found in small depressions and in the larger wetland in areas that are flooded for long periods. The most obvious difference with community 10 is the absence of Cynodon dactylon. The pans are sometimes fringed by the tree Combretum imberbe. Other important grass species are Sporobolus consimilis, Eragrostis cf. heteromera, cf. Acroceras macrum and Echinochloa colona. In deeper water, dense stands of Phragmites australis or P. mauritianus reeds and bulrushes Typha capensis are found. These could not be sampled because of problems in terms of accessibility. The blue water lily Nymphaea nouchali, as well as the small yellow water lily Nymphoides thunbergiana and the white-flowered Nymphoides indica ssp. occidentalis are very conspicuous.

The communities described above are very dynamic in nature. As waters recede, com- 
munity 11 gives way to community 10 . Community 10 can become more wooded if flooding does not occur for a number of years, it also being encroached upon by expanding Acacia borleae of community 8 . Stands of $5 \mathrm{~m}$ tall dead Acacia xanthophloea and mopane have been observed. This indicates that trees could establish themselves and thrive for a number of years before being killed during a long period of inundation.

\section{Wetland types of the PNB}

The wetlands of the PNB are characterised by episodic flooding from sporadic storm events that produce ephemeral flows followed by a gradual drying out. This process is determined not only by the amount of rainfall, but also by the intensity and duration of the event. These factors, along with levels of soil saturation, determine how much of the catchment runoff reaches the wetland. The right conditions mainly tend to occur when tropical cyclones move in over the PNB catchment from the Mozambique Channel, mainly during the period December to March.

Such a hydrological regime means that water flows in to the wetland system only as a result of intense and sporadic storm events. These driving pulses result in a high degree of diversity and productivity within the PNB's wetland systems. The continuous transition between the terrestrial and aquatic condition as a result of the cyclic flooding and drying of the PNB system creates a dynamic ecotone supporting an array of diverse temporal habitats and rich fauna and flora. The pulsed nature of inflows from within the catchment brings with it a rich sediment load high in nutrient content. As a result of this pattern, and the concentration

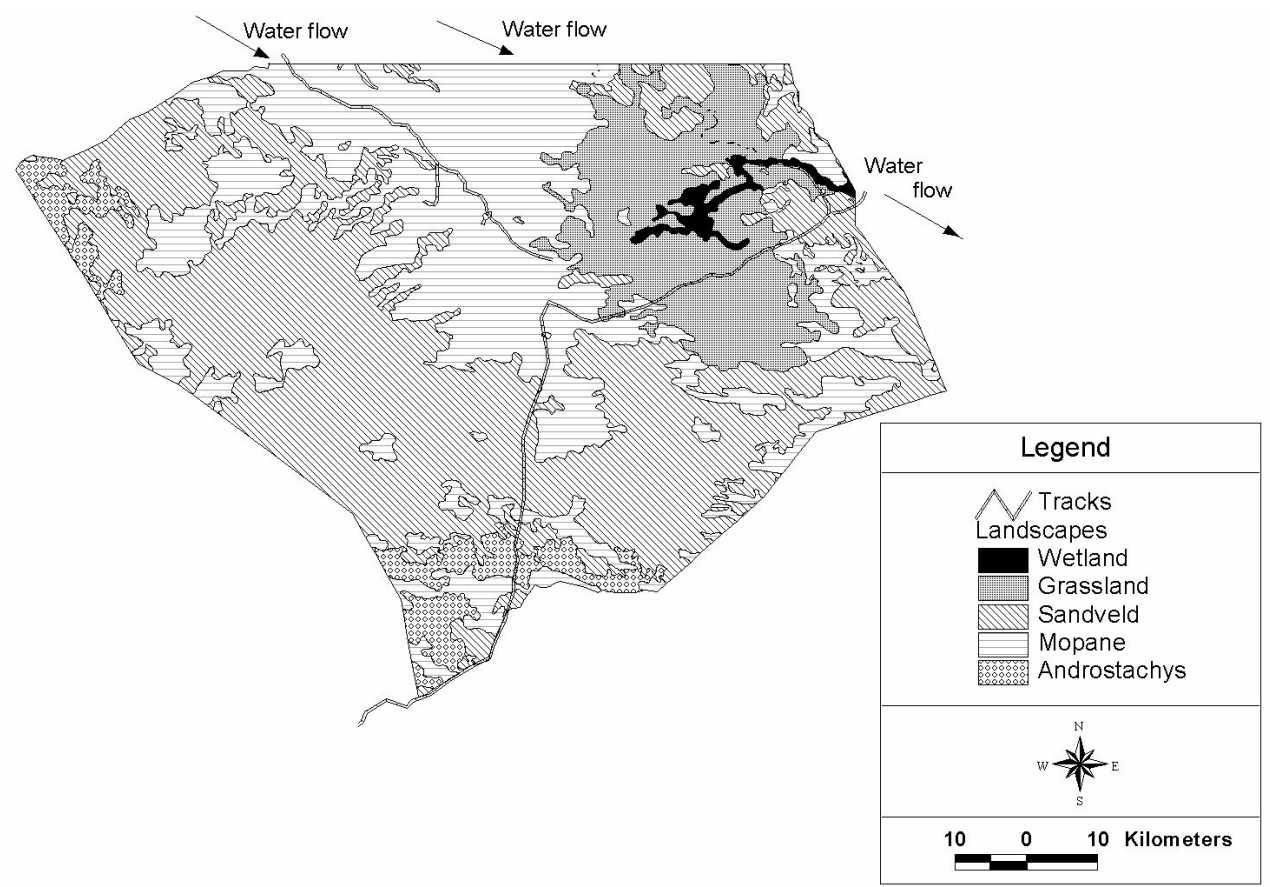

Fig. 7. Landscape map of the Parque Nacional de Banhine. 
affected through high evaporation rates, nutrient levels within some of the smaller wetland systems would appear to be extremely high.

The following six wetland types (based on the Ramsar Convention classification) occur in the park:

L Permanent inland deltas;

M Permanent rivers/streams/creeks;

$\mathrm{N}$ Seasonal/intermittent/irregular rivers/streams/ creeks;

P Seasonal / intermittent freshwater lakes ( $>8 \mathrm{ha}$ ) including floodplain lakes;

Tp Permanent freshwater marshes/pools; ponds (below 8ha), marshes and swamps on inorganic soils; with emergent vegetation water-logged for at least most of the growing season;

Ts Seasonal/intermittent freshwater marshes/ pools on inorganic soils; includes sloughs, potholes, seasonally flooded meadows, sedge marshes.

\section{Landscapes of the PNB}

Not all of these 11 plant communities can be mapped individually, not even using the results of the satellite imagery analysis. They often occur in a fine-scaled mosaic that reflects small variations in topography and accompanying moisture regime. These factors cannot always be mapped in sufficient detail to allow for extrapolation and correlation with the vegetation. Broader units have thus been mapped out of necessity.

Landscapes have been defined that have bearing on management requirements and development potential as they represent a composite of topographical factors, underlying soil, hydrology and current vegetation pattern. Different combinations of the plant communities can be grouped in five major landscapes. Extensive use was made of the existing "Carta de Uso e Cobertura da Terra" (Anonymous 1999) for the mapping of the following individual landscapes (Fig. 7):

Wetland landscape - comprises the seasonally to permanently flooded areas in the northeastern part of the park, particularly towards Pio Cabral. This landscape is characterised by community 11, although communities 9

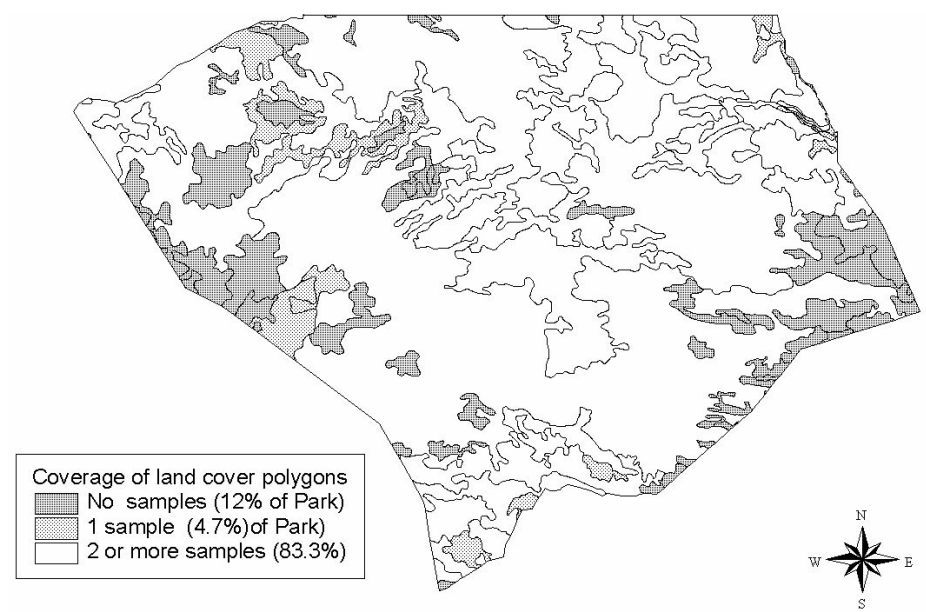

30 0 60 Kilometers

Fig. 8. Sampling intensity across original land cover polygons in the Parque Nacional de Banhine. Polygons with no or only one sample indicate greater uncertainty as to their correct landscape classification. 
\& 10 occur on levees and patches of higher ground within the landscape. Large areas of open water with dense stands of Phragmites australis/mauritianus reeds, Typha capensis and sedges occur. This landscape holds examples of wetland types $\mathrm{L}$ and $\mathrm{Tp}$ as described earlier. It covers 6588 ha or $1.1 \%$ of the PNB. Wattled cranes Grus carunculatus have been observed in the wetland landscape during 2002, 2003 and 2004 (M. Stalmans pers. obs.).

Grassland landscape - this landscape represents the seasonally flooded areas surrounding the wetland landscape. Its characteristic feature is its open grasslands (community 10), sometimes with scattered trees (community 9), bush clumps on termitaria (community 2) and Acacia borleae shrublands (community 8) and Hyphaene petersiana - Terminalia sericea trees (community 7) on its margins. 'Islands' of sandveld, Colophospermum mopane and baobabs Adansonia digitata with Commiphora spp. occur on slightly higher ground within the extensive grasslands. This landscape represents the flooded meadows of wetland type Ts with seasonal pans as well as larger seasonal floodplain lakes of wetland type P. It covers 85170 ha or $13.6 \%$ of the PNB. The Grassland landscape is very important to the large popula- tion of ostriches Struthio camelus that is found in the park. Oribi Ourebia ourebi occur in this landscape, particularly towards the ecotone with the Wetland landscape.

Mopane landscape - this landscape is found on more loamy to clayey soils, specifically where the sand mantle has been eroded away, to the north-west of the wetland and grassland landscapes. Its dominant feature is the closed woodlands of communities $4 \& 5$. Embedded within the mopane are the seasonal streams representing wetland type $\mathrm{N}$ (with vegetation community 3 ). These streams channel water from the areas north of the park towards the wetland above the alluvial plug. Further downstream these streams become ill-defined, with an almost 'braided' character. They are wide and grassy, covered by communities $9 \& 10$, with community 11 in small pans within those illdefined drainage lines. This landscape therefore holds elements of wetland types $\mathrm{N}$ and Ts. It covers 212226 ha or $33.9 \%$ of the Parque Nacional de Banhine.

Sandveld landscape - this landscape covers the larger part of the park, particularly to the west and south. It typically consists of community 6 with patches of community 5 . Pans in this landscape are covered by community 11. Wetland type Ts is therefore represented.

Table 1

Relative species richness of plant communities in the PNB

\begin{tabular}{lccccc}
\hline Community & $\begin{array}{c}\text { No. of } \\
\text { sample } \\
\text { plots }\end{array}$ & $\begin{array}{c}\text { Total } \\
\text { species }\end{array}$ & $\begin{array}{c}\text { Expected no. } \\
\text { of species }\end{array}$ & $\begin{array}{c}\text { Actual no. } \\
\text { as \% of } \\
\text { expected }\end{array}$ & $\begin{array}{c}\text { Relative } \\
\text { diversity }\end{array}$ \\
\hline 1 & 5 & 9 & 18 & 50 & Medium \\
2 & 5 & 22 & 18 & 123 & Medium \\
3 & 3 & 29 & 11 & 259 & High \\
4 & 28 & 81 & 96 & 85 & Medium \\
5 & 22 & 102 & 75 & 135 & High \\
6 & 13 & 83 & 45 & 185 & High \\
7 & 7 & 24 & 25 & 97 & Medium \\
8 & 2 & 9 & 8 & 115 & Medium \\
9 & 13 & 26 & 45 & 58 & Low \\
10 & 12 & 9 & 42 & 22 & Low \\
11 & 5 & 6 & 18 & 33 & Low \\
\hline
\end{tabular}


This is the most extensive landscape and covers 292350 ha or $46.7 \%$ of the PNB. This is similar to the situation in the Limpopo National Park where the Nwambia sandveld landscape covers $41 \%$ of the park. Sandveld is not well represented in the Kruger National Park on the South African side of the Greater Limpopo Transfrontier Park.

Androstachys (Nsimbitsi) landscape - this landscape is very uniform and mostly consists of community 1 . It is interleaved with the sandveld landscape in the extreme northwestern corner of the park and with the mopane and sandveld landscapes in the extreme south. It covers 29688 ha or $4.7 \%$ of the PNB.

The map boundaries are drawn subjectively because of the fact that there is seldom a definite and visible border between landscapes, but rather a gradient in terms of vegetation and topography. The sampling did not cover all land cover polygons (Fig. 8), with $12 \%$ of the PNB not being assessed at all. The greatest uncertainties with regard to the landscape map are along the western boundary and in the south-eastern corner of the PNB.

\section{Plant community and landscape diversity}

The available time frame and limited ground coverage did not allow for a detailed inventory of plant diversity. However, a relative measure of plant community diversity can be derived by comparing the total species count to the sampling intensity for each respective community. The number of species per community in relation to the expected species number (based on the average accumulated number of species per sample plot) is depicted in Table 1.

Communities 3 (riverine), 5 (partly sandveld) and 6 (pure sandveld) are relatively more species-rich than expected from the number of samples assessed. In particular, the sandveld of community 6 much exceeds the expected value. The same applied for sandveld in the Limpopo National Park (Stalmans et al. 2004).

Land use patterns and their influence on the vegetation of the $P N B$

A number of people reside within the boundaries of the PNB. They practise mainly subsistence farming and rely on the fish resources of the wetland. Subsistence farming takes mostly place on bushclumps, in mopane woodlands and in the wetland. Bushclumps of community 2 are cleared and maize is planted in the fertile soil of the termitarium. The number of bushclumps that have been destroyed in this manner seems fairly limited. However, it can be anticipated that recovery will take many years. The whole functioning (and therefore recovery) may be affected by the loss of the emergent Xanthocercis zambesiaca trees. Manual clearing of mopane woodlands (communities $4 \& 5$ ): with stacking of the material around the bigger trees is followed by burning that kills those trees. Crops are planted in the ashbed that increases fertility. Crops can only be produced for a very few years before these lands must be left fallow to restore soil fertility. The total area that has been cleared and is in some stage of recovery is therefore much larger than the extent of land that is actively cultivated in any given year. As waters recede, crops are planted in the wetland (community 11). The extent of cultivated land is relatively limited and the impact is probably fairly small as the next flood cycle probably 'resets' the cultivated patch and surrounding areas to a similar state.

Use is made of trees for firewood, building of dwellings, livestock pens, and carving of various items. The impact of these activities is selective. Whereas this use does not seem to impact significantly on the overall woody resource, no data are available on the impact on specific species. Grass is cut and used for thatching (mostly Heteropogon contortus). Much use is made of medicinal plants and wild fruits (eg. Strychnos spp.). No data are available regarding the impact thereof on specific species. The Hyphaene palms are 
heavily tapped for their sap. This involves the cutting of the stems. As a result very few tall palms have been observed in the field.

The Devil's claw Harpagophytum procumbens (family Pedaliaceae) occurs in the PNB (Dr A.B. (Tony) Cunningham pers. comm. 2003). The root tubers of this plant are traded internationally and concern has been expressed at the CITES level regarding its situation (Anonymous 2003).

Levels of herbivory (both grazing and browsing) seem presently very limited in the PNB. Current numbers of game are certainly very low. Livestock numbers are also relatively limited including cattle and goats. During the subjective scoring of the sample plots only 7 out of 115 plots had a medium level of grazing pressure and one had a medium browsing impact (old elephant utilisation). No heavy grazing was observed. The grass and tree layer are generally in a good condition. It offers suitable habitat for the herbivores that could be expected in this environment (both those occurring historically and those still present).

The only alien plant species observed was the prickly pear (Opuntia sp.). It occurs in a few dense stands near the village of Tchove.

Fires are very prominent within the PNB with signs of old and recent fire events visible throughout the landscape. Although a number of fires likely originate from lightning, the most probable cause of fire is through the activities of the inhabitants of the PNB, e.g., clearing of lands, producing a green flush for livestock grazing, smoking out of beehives. Within the constraints of the present study it was not possible to assess the fire return period and its appropriateness. Of interest is the relatively small-scale pattern that can be observed in the field. This pattern of spatially and temporally varying fire parameters (frequency, seasonality, intensity and type of fire) across the landscape is likely to be required for the maintenance of diversity (Brockett et al. 2001; Gill \& McCarthy 1998).

\section{Acknowledgements}

Dr Ken Tinley provided unpublished data which he collected during the 1970s. These data proved invaluable in describing the functioning of this wetland system. Warden Armando Nguenya provided logistical support and accompanied the survey team in the field. Dr Jeremy Anderson assisted with access to the area, provided assistance with the vegetation sampling and organised over flights of the PNB. Members of the Bateleur group of pilots (in particular Joe Holmes and Avroy Shlain) graciously provided fixed-wing and micro-light flying time. Craig Beech of the Peace Parks Foundation assisted with GIS data. Mervyn Lötter, Ernst Schmidt, Warren McLeland and John Burrows of the Plant Specialist Group assisted with species identification. The vegetation and hydrological research was undertaken as part of the planning work by Development Alternatives Inc that was funded by USAID in support to the Direcção Nacional de Áreas de Conservação of the Ministério do Turismo, Moçambique. More specifically, the management plan for the PNB was compiled by the ecologists Dr D Grossman and Ms P Holden.

\section{References}

ANONYMOUS. 1995. Legenda da carta nacional de solos (Escala 1:1.000.000). Maputo, Moçambique: Compilada pelo Departemento Terra e Agua.

ANONYMOUS, 1997. First national report on the conservation of biological diversity in Moçambique. Ministry for the Coordination of Environmental Affairs. Maputo.

Anonymous. 1999. Carta de Uso e Cobertura da Terra. Moçambique: Joint venture IGNFI CENACARTA - DINAGECA.

AnONYMous. 2002. Banhine National Park, Management and Development Plan. Unpublished report to the National Directorate for Conservation Areas, Ministry of Tourism, Republic of Moçambique.

AnONYMOUS. 2003. Devils' claw (Harpagophytum procumbens). Fauna \& Flora 4 (April 2003): 28.

Brockett, B.H., H.C. Biggs \& B.W. Van Wilgen. 2001. A patch mosaic burning system for conservation areas in southern African savannas. International Journal of Wildland Fire 10:169183.

Coetzee, B.J. 1983. Phytosociology, vegetation structure and landscapes of the Central District, Kruger National Park. Dissertationes Botanicae 69: 1-456. 
EDWARDS, D. 1983. A broad scale structural classification of vegetation for practical purposes. Bothalia 14: 705-712.

Gabriel, H.W. \& S.S. TAlbot. 1984. Glossary of landscape and vegetation ecology for Alaska. BLM-Alaska Technical Report 10. U.S. Department of the Interior.

GAUCH, H.G. 1982. Multivariate analysis in community ecology. Cambridge: University Press.

GertenBACH, W.P.D. 1983. Landscapes of the Kruger National Park. Koedoe 26:9-121.

Gill, A.M. \& M.A. McCARTHY. 1998. Intervals between prescribed fires in Australia: what intrinsic variation should apply? Biological Conservation 85:161-169.

HiLl, M.O. 1979. TWINSPAN - A FORTRAN program for arranging multivariate data in an ordered twoway table by classification of the individuals and attributes. Ithaca, New York: Cornell University.

Jongman, R.H.G., C.F.J. TER BRAAK \& O.F.R. VAN TONGEREN. 1987. Data analysis in community and landscape ecology. Wageningen: Pudoc.

Kelly, R.D. \& B.H. Walker. 1976. The effect of different forms of land use on the ecology of a semi-arid region in South-eastern Rhodesia. Journal of Ecology 64:553-576.

Land Type Survey Staff. 1989. Land types of the map 2530 Barberton. Memoirs of the Agricultural Natural Resources of South Africa 13.

LeEmans, R. \& W. CRAMER. 1991. The IIASA database for mean monthly values of temperature, precipitation and cloudiness of a global terrestrial grid. International Institute for Applied Systems Analysis (IIASA). RR-91-18.

Matthews, W.S., A.E. VAN WyK \& N. VAN RoOyen. 1999. Vegetation of the Sileza Nature Reserve and neighbouring areas, South Africa, and its importance in conserving the woody grasslands of the Maputaland Centre of Endemism. Bothalia 29(1):151-167.

Mueller Dombois, D. \& H. Ellenberg. 1974. Aims and methods of vegetation ecology. New York: John Wiley.

National Working Group For Vegetation EcoloGY. 1986. Soil classification according to the binomial classification system. Technical Communication 3 .

Scholes, R.J. \& B.H. Walker. 1993. An African savanna. Cambridge Cambridge: University Press.

Siebert, F., G.J. Bredenkamp \& S.J. Siebert. 2003. A comparison of Mopaneveld vegetation in South Africa, Namibia and Zimbabwe. Bothalia 33(1):121-134.

Stalmans, M. 1994. Vegetation survey of Malilangwe. Unpublished report to the Malilangwe Conservation Trust.

Stalmans, M., W.P.D Gertenbach \& F. CarvalhoSERFonteIn. 2004. Plant communities and landscapes of the Parque Nacional do Limpopo, Moçambique. Koedoe 47(2): 61-81.

TER BrAAK, C.J.F. 1986. Canonical correspondence analysis: a new eigenvector technique for multivariate direct gradient analysis. Ecology 67(5): 1167-1179.

Ter BraAK, C.J.F. 1992. CANOCO - A Fortran program for canonical community ordination. Ithaca, New York, USA: Microcomputor Power.

Timberlake, J.R., N. NobandA \& I. Mapaure. 1993. Vegetation survey of the communal landsnorth and west Zimbabwe. Kirkia 14(2): 171270.

VAn Rooyen, N., G.K. Theron \& N. GrobbelaAr. 1981. A floristic description and structural analysis of the plant communities of the Punda Milia-Pafuri-Wambiya area in the Kruger National Park, Republic of South Africa: 2. The sandveld communities. Journal of South African Botany 47(3):405-449.

Werger, M.J.A. \& B.J. Coetzee. 1978. The Sudano-Zambezian Region. In: Werger, M.J.A. (ed.). Biogeography and ecology of southern Africa. The Hague: W. Junk.

Wetzel, R.G. 2001. Limnology: lake and river ecosystems. 3rd Edition. San Diego: Academic Press.

WiLD, H. \& L.A.G. BArbosA. 1967. Supplement of the vegetation map of the Flora zambesiaca area. Pp. 1-71. In: WiLd, H. \& A. Fernandes. Vegetation map of the Flora zambesiaca region. Harare, Zimbabwe. 